\title{
Phenotypic correlations between body weight and morphometric traits in broiler
} chicken strains

${ }^{1}$ Nosike, R. J., ${ }^{1}$ Obasi, E. N., ${ }^{2}$ Nwose, R. N., ${ }^{3}$ Igwe, R. O., ${ }^{1 *}$ Onunkwo, D.

N., ${ }^{1}$ Amaduruonye, W., ${ }^{1}$ Nwakpu, O. F. and ${ }^{1}$ Inyang, E. C.

${ }^{1}$ College of Animal Science and Animal Production, Michael Okpara University of Agriculture, Umudike, Abia State, Nigeria

${ }^{2}$ Department of Agriculture, Alex Ekweume University, Ikwo, Ebonyi State, Nigeria

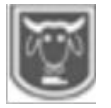

${ }^{3}$ Department of Animal Science, Ebonyi State University, Abakailiki, Ebonyi State, Nigeria

Abstract *Corresponding author: donunkwo1@gmail.com., +2348033388622 A total of 270 one day-old broiler chicks comprising of 90 chicks each of Abor Acre, Ross and Marshal Strains were used for the study. The study was carried out to determine the correlation between the body weight and other morphometric measurements in the broiler strains from 2 to 8 weeks of age and predict body weight of the broiler using linear body measurement. Data were collected on body weight and body measurements to include breast length (BRL), thigh width (TW), shank length $(S L)$, keel length $(K L)$, wing length and drumstick length $(D L)$. There were strong positive and significant $(p>0.01)$ correlations between body weight (BWT) and all morphometric traits in the three broiler strains studied, except breast length (BRL) that showed weak but significant $(p<0.01)$ correlations. Also correlations among the morphometric traits were significant $(p<0.01)$ in the broiler strains except for correlation between shank length (SL) and (BRL). Specifically, significant and strong positive correlations were observed between TWD and BW(rp=0.89), BL and BW(rp $=0.91)$, KL and BW (rp = 0.89) in Arbor Acre broiler Strain. In Marshall, significant and positive correlations were obtained between TWD and BW (rp =0.89), KL and TWD (rp = 0.91), KL and BW (rp = 0.89) in Arbor Acre broiler Strain. Similarly, in Rosss strain, strong positive correlations were observed between $T W D$ and $B W(r p=0.89), B L$ and $B W(r p=$ 0.90), KL and TWD (rp =0.91). All other correlations were positive, weak or moderate.

The phenotypic correlation between body weight and linear body parameters were positive and significant, which implies that increase in one body trait will lead to increases in the other.

Keywords: Phenotypic correlations, broiler strains, body weight morphometric traits

\section{Introduction}

There has been a call for substantial increase in the intake of protein of animal origin in developing countries like Nigeria. This can be achieved through the production of animals that are prolific and have short generation interval (Abeke et al., 2003). Poultry breeders need some techniques to select animals for breeding purposes. The knowledge of interrelationships among body measurements can be applied in selection and breeding (Monsi, 1992). Chambers and
Fortin (1984) reported that the importance of evaluating interrelationships and conformation traits in poultry lies in their usefulness as predictors of characteristics like body weight. Such application could speed up the assessment of traits through the involvement of simple measurement tools like ruler, as such simple linear measurements that can predict body weight without necessitating bird slaughter will be particularly desirable. Although many strains of broiler chicken have been imported into Nigeria, the performance of 


\section{Phenotypic correlations between body weight and morphometric traits in broiler chicken strains}

these birds is affected by genotype $\mathrm{x}$ environment interaction. Genotype by environment interaction may cause loss of fitness traits for those genotypes not suited to our environment. Therefore, broiler producers will be able to invest in rearing those strains that are best suited in a particular environment. Although separate effect of strain and sex on broiler chicken performance has been widely reported in literature, their interaction has not been given much attention. Ajayi and Ayorinde (2009) reported significant strain by sex interaction on live weight, weight gain and carcass traits of broiler chickens. The morphometric measurements vary positively with age of the animals and the correlations of body weight with diagonal body length, height at wither, sac pelvic width and hearth girth were reported to be high, positive and significant (Ojedapo, et al., 2007). With the measurement of some body parameters, the age of animals can be assessed and the timing for different management practices can be pegged accurately to bring animals to good and desired weight at maturity (Imasenen and Otoikhian, 2004). There is need for breeders to breed desirable sizes of chicken with desirable production traits particularly body weight and other morphometric measurements. The objective of the study was to determine the correlation between the body weight and other morphometric measurements in the commercial broiler chicken strain.

\section{Location of study}

The experiment was carried out at the Poultry Unit, Teaching and Research Farm, Michael Okpara University of Agriculture, Umudike, Umuahia, Abia State. The teaching and research farm has annual rainfall of $2177 \mathrm{~mm}$, temperature range of $22^{\circ} \mathrm{C}-36^{\circ} \mathrm{C}$ and relative humidity above $50 \%-90 \%$ (NRCRI). It is located at latitude $05^{\circ} 29$ North and $07^{\circ} 32$ East on an elevation of about $122 \mathrm{~m}$ above sea level; these metrological data were obtained from the metrological station at the National Root Crops Research Institute, Umudike, Abia State.

\section{Experimental birds and management}

A total of 270 broiler chicks comprising of 90 chicks each for Arbor Acre, Ross and Marshall Strains were used for the study. The chicks were purchased from a reputable hatchery in Nigeria. The experimental birds were grouped into 3 treatments (strain) replicated 5 times with 18 birds per replicate.

The brooding house was partitioned into pens in line with the design of the experiment. The floor of the brooding pens was covered with wood shaving and they will be kept dry throughout the experiment period by replacing the wet litter with new ones. Electricity, lantern and stoves was used to heat up the brooding house, shallow plastic feeders and chick fonts was used to provide feed and water to the chicks, respectively. Health management practices were used carried out on the broiler chicks. The chicks were given anti-stress at arrival to boost their energy level. They were given Newcastle Disease Vaccine (NDV) intraocular (I/0). Coccidiostat and other antibiotics were also administered via drinking water. Birds were also dewormed and acaricide sprayed to check worms and ecto-parasites, respectively. The chicks were fed ad-libtum on a commercial broiler starter diet containing $21 \% \mathrm{CP}$ and $2900 \mathrm{Kcal} / \mathrm{kg} / \mathrm{me}$ from $1-4$ weeks of age followed by a finisher diet containing $19 \%$ $\mathrm{CP}$ and $3000 \mathrm{Kcal} / \mathrm{me}$ from $5-8$ weeks of age and water was fed ad-libtum.

\section{Data collection}

Body weight was measured weekly using a top loading $20 \mathrm{~kg}$ scale with sensitivity of $10 \mathrm{~g}$, thigh weight was taken from the beginning of the fabula to the hock joint; shank length was taken from the beginning 


\section{Nosike, Obasi, Nwose, Igwe, Onunkwo, Amaduruonye, Nwakpu and Inyang}

of the hock joint to the last ring before the tarsal or meta-tarsal digit, breast width was measured from the point of depression to the sharp edge, keel length was measured from the V-joint to the end of the sternum, drumstick length was measured as the Length of the Femur bone, wing length was the distance between the tip of the phalanges and the coracoids-humerus joint, body length was the distance between the base of the neck and pygostlye. The body traits were measured using tailor's $(\mathrm{cm})$ tape and body weight with weighing scale.

\section{Data analysis}

Data were statistically analyzed using Statistical Package for the Social Sciences (SPSS) version 20.0.

Correlation among BWT and morphometric measurements were carried out different strains using Pearson's Product Moment Correlation Coefficient ${ }^{\circledR}$.

\section{Results and discussion}

Correlations among body weight and morphometric traits of broiler strains

The correlations among body weight and morphometric traits are presented in Tables 1, 2 and 3 for Arbor Acre, Ross and Marshal, respectively. There were strong positive and significant $(p<0.01)$ correlations between BWT and all the morphometric traits in the three broiler strains studied, except for BRL that showed weak but significant $(p<0.01)$ correlations. This implies that increase in any of these traits will lead to increase in BWT and vice versa. This result agreed with report by Okoro and Ogundu (2006) that high and positive phenotypic correlations exist between body weight and other body parameters (thigh length, chest circumference, breast width, keel length and shank length). However, significant ( $p$ $<0.01$ ) and strong positive correlations were observed between TWD and BW (rp = $0.89), \mathrm{BL}$ and BW (rp = 0.91), KL and BW $(\mathrm{rp}=0.89)$ in Arbor Acre broiler Strain.

Similarly, in Ross Strain, there were strong positive and significant $(\mathrm{p}<0.01)$ correlations between TWD and BW (rp = $0.89), \mathrm{BL}$ and $\mathrm{BW}(\mathrm{rp}=0.90)$, KL and TWD $(\mathrm{rp}=0.91)$. All other correlations were positive, weak or moderate.

Table 1: Correlation among BWT and morphometric traits in Arbor Acre broiler Strain

\begin{tabular}{llllllll}
\hline Strain/parameter & BW & BRL & TWD & SL & BL & KL & WL \\
\hline BRL & $0.279^{* * *}$ & 1 & & & & \\
TWD & $0.894^{* *}$ & $0.222^{* *}$ & 1 & & & \\
SL & $0.791^{* *}$ & $0.190^{* *}$ & $0.795^{* *}$ & 1 & & & \\
BL & $0.908^{* *}$ & $0.276^{* *}$ & $0.865^{* *}$ & $0.779^{* *}$ & 1 & & \\
KL & $0.894^{* *}$ & $0.402^{* *}$ & $0.898^{* *}$ & $0.821^{* *}$ & $0.881^{* *}$ & 1 & \\
WL & $0.830^{* *}$ & $0.222^{* *}$ & $0.797^{* *}$ & $0.729^{* *}$ & $0.788^{* *}$ & $0.821^{* *}$ & 1 \\
DSL & $0.851^{* *}$ & $0.230^{* *}$ & $0.816^{* *}$ & $0.695^{* *}$ & $0.818^{* *}$ & $0.828^{* *}$ & $0.766^{* *}$ \\
\hline
\end{tabular}

**. Correlation is significant at the 0.01 level (2 -tailed).; BRL-Breast length; TWD - Thigh width; SL - Shank length; BL Body length; KL- Keel length; WL- Wing length; DSL- Drumstick length, BW-Body weight; NS-Not Significant.

Table 2: Correlations among BWT and morphometric traits of Ross broiler strain

\begin{tabular}{llllllll}
\hline Strain/parameter & BW & BRL & TWD & SL & BL & KL & WL \\
\hline BRL & $0.453^{* *}$ & I & & & & & \\
TWD & $0.894^{* *}$ & $0.417^{* *}$ & 1 & & & & \\
SL & $0.772^{* *}$ & $0.332^{* *}$ & $0.780^{* *}$ & 1 & & & \\
BL & $0.900^{* *}$ & $0.472^{* *}$ & $0.869^{* *}$ & $0.793^{* *}$ & 1 & & \\
KL & $0.891^{* *}$ & $0.429^{* *}$ & $0.915^{* *}$ & $0.783^{* *}$ & $0.867^{* *}$ & 1 & \\
WL & $0.843^{* *}$ & $0.418^{* *}$ & $0.823^{* *}$ & $0.749^{* *}$ & $0.825^{* *}$ & $0.845^{* *}$ & 1 \\
DSL & $0.847^{* *}$ & $0.525^{* *}$ & $0.833^{* *}$ & $0.658^{* *}$ & $0.812^{* *}$ & $0.857^{* *}$ & $0.807^{* *}$ \\
\hline
\end{tabular}

**. Correlation is significant at the 0.01 level (2 -tailed).; BRL-Breast length; TWD - Thigh width; SL - Shank length; BL Body length; KL- Keel length; WL- Wing length; DSL- Drumstick length, BW-Body weight; NS-Not Significant. 
Phenotypic correlations between body weight and morphometric traits in broiler chicken strains

In Marshall Strain, significant $(\mathrm{p}<0.01)$ and positive correlations were obtained between TWD and BW (rp = 0.89), KL and
TWD $(\mathrm{rp}=0.91)$, KL and BW $(\mathrm{rp}=0.89)$ in Arbor Acre broiler Strain.

Table 3: Correlations among body weight and morphometric traits of Marshall Broilers

\begin{tabular}{llllllll}
\hline Strain/parameter & BW & BRL & TWD & SL & BL & KL & WL \\
\hline BRL & $0.321^{* *}$ & & & & & & \\
TWD & $0.894^{* *}$ & $0.300^{* *}$ & & & & \\
SL & $0.745^{* *}$ & 0.161 & $0.757^{* *}$ & 1 & & \\
BL & $0.856^{* *}$ & $0.359^{* *}$ & $0.833^{* *}$ & $0.726^{* *}$ & 1 & & \\
KL & $0.898^{* *}$ & $0.258^{* *}$ & $0.911^{* *}$ & $0.798^{* *}$ & $0.837^{* *}$ & 1 & \\
WL & $0.794^{* *}$ & $0.316^{* *}$ & $0.796^{* *}$ & $0.721^{* *}$ & $0.760^{* *}$ & $0.838^{* *}$ & 1 \\
DSL & $0.880^{* *}$ & $0.425^{* *}$ & $0.858^{* *}$ & $0.677^{* *}$ & $0.830^{* *}$ & $0.862^{* *}$ & $0.803^{* *}$ \\
**. Correlation is significant at the 0.01 level (2 -tailed).; BRL -Breast length; TWD - Thigh width; SL - Shank length; BL - \\
Body length; KL - Keel length; WL - Wing length; DSL - Drumstick length, BW-Body weight; NS -Not Significant.
\end{tabular}

According to Pundir et al. (2011) the positive and significant correlation among the body measurement observed in the 3 strains indicated high predictability among the variables. The positive correlation between body weight and all of the linear body measurements showed that body weight can be predicted from the linear body measurement. Ajayi et al. (2008) and Amao et al. (2012) reported similar correlations. The linear parameter with the highest value of coefficient of correlation with the body weight in Arbor Acre, Ross and Marshall Strains were body length (0.908) and Keel length (0.898) respectively. These parameters are considered to give better accuracy of prediction of body weight in their different strains.

\section{Conclusion}

The phenotypic correlation between body weight and linear body parameters were positive and significant, which implies that increase in one body trait will lead to increases in the other.

\section{References}

Abeke, A. O., Ogundipe, S. O., Sekoni, A. A., Adeyinka, I. A., Abubakar, B. Y., Oni, O. O. and Nwagu,
B. I. 2003. Response of laying hens to dietary levels of treated sheep manure, Tropical

Journal of Animal Science, 2: 111-116.

Ajayi, F. O. and Ayorinde, K. L. 2000. Effect of sex on some growth criteria in Cobb broiler strain. 5th Annual Conference of Animal Science Association of Nigeria, 5:49-52.

Ajayi, F. O., Ejiofor, O. and Ironke, M. O. 2008. Estimation of body weight f r o $\mathrm{m}$ L i n e a $\mathrm{r}$ B o d y Measurements in two commercial meat-type chickens. Global Journal of Agricultural Science, 7(1): 6772.

Amao, S. R., Ojedapo, L. O., Oyewumi, S. O. and Olatunde, A. K. 2012. B o d y C o n f or m a t i o n characteristics of Marshall Strain of commercial broiler chickens reared i $n \quad d$ e rived s a v a n a environment of Nigeria. In: Proceedings of the 37th Nigerian Society of Animal Production Conference, 37: 1-3

Chambers, J. R. and Fortin, A. 1984. Live body and carcass measurements as predictors of chemical composition of carcass of male broiler chickens. 
Poultry Science Journal, 63: 21872196. 100

Monsi, A. 1992. Appraisal of interrelationships among live body measurements at different ages in meat type chickens, Nigerian Journal of Animal Production.19 $(1,2): 15-24$.

Okoro, V. M. O. and Ogundu, U. E. 2006. Genetic variabilities of growth traits in two Turkey breeds in $\mathrm{S}$ o $\mathrm{u} \mathrm{t} \mathrm{h}$ Eastern Nigeria. In: Proceedings of the 13th Annual Conference of the Nigerian Society of Animal Production (13): 5-8
Pundir, R. K., Singh, P. K. and Dangi, P. S. 2011. Factor analysis of biometric traits of Kankrej cows to explain body conformation. AsianAustralian Journal of Animal Science 24 (4): 449-456.

SPSS 2011. Statistical Package for Social Sciences. SPSS Version 20 IBM Inc. 444 Michigan Avenue, Chicago, IL60611, USA.

Received: $12^{\text {th }}$ May, 2018

Accepted: $31^{\text {st }}$ August, 2018 